\title{
Cantinas escolares de Florianópolis: existência e produtos comercializados após a instituição da Lei de Regulamentação ${ }^{1}$
}

\author{
School canteens of Florianópolis: existence \\ and foods for sale after the institution \\ of the law of regulation
}

Cristine Garcia GABRIEL ${ }^{2}$

Melina Valério dos SANTOS²

Francisco de Assis Guedes de VASCONCELOS 3

Gladys Helena Gonçalves MILANEZ ${ }^{4}$

Sanlina Barreto HULSE ${ }^{5}$

RE S U M O

\section{Objetivo}

Realizar um diagnóstico da existência das cantinas em Florianópolis, verificando os alimentos e bebidas comercializados, após a instituição da Lei Estadual de Regulamentação das Cantinas.

\section{Métodos}

Questionário estruturado foi aplicado por telefone com os diretores ou responsáveis pelas cantinas do universo de escolas de ensino fundamental das redes municipal, estadual e particular de Florianópolis. Os dados foram processados e analisados utilizando-se o software SPSS versão 10.0.

\section{Resultados}

Das 117 instituições do município em 2006, 89,7\% aceitaram participar. Dessas, 53,3\% possuem cantina, sendo 31 particulares, 22 estaduais e apenas 3 municipais. Os principais motivos referidos para a ausência de cantinas nas escolas públicas consistiram na existência do Programa de Alimentação Escolar e nas exigências para sua adequação à Lei. Dentre os alimentos proibidos pela Lei, salienta-se que os salgados fritos e industrializados não são mais comercializados pelas escolas, e a maioria não comercializa mais refrigerantes $(98,2 \%)$ e pipocas industrializadas (92,9\%). Ressalta-se, também, que os sucos naturais e os salgados assados são comercializados por $75,0 \%$ e $98,2 \%$ das escolas, respectivamente. Por outro lado, 60,7\% das escolas

1 Apoio: Conselho Nacional de Desenvolvimento Científico e Tecnológico (Processo: 402334/2005-1).

2 Universidade Federal de Santa Catarina, Centro de Ciências da Saúde, Departamento de Nutrição. Caixa Postal 476, Trindade, 88040-970, Florianópolis, SC, Brasil. Correspondência para/Correspondence to: C.G.GABRIEL. E-mail: <cris_ntr@hotmail.com>.

3 Universidade Federal de Santa Catarina, Centro de Ciências da Saúde, Departamento de Nutrição. Florianópolis, SC, Brasil.

${ }^{4}$ Governo do Estado de Santa Catarina, Secretária Estadual de Educação. Florianópolis, SC, Brasil.

5 Prefeitura Municipal de Florianópolis, Secretaria Municipal de Educação. Florianópolis, SC, Brasil. 
192 | C.G. GABRIEL et al.

comercializam sucos artificiais. Ainda de acordo com a Lei, as cantinas deverão disponibilizar dois tipos de frutas sazonais. No entanto $60,7 \%$ dos estabelecimentos não disponibilizam frutas ou salada de frutas.

\section{Conclusão}

Itens proibidos pela Lei foram fortemente reduzidos ou retirados de comercialização, porém alimentos considerados inadequados continuam sendo comercializados em muitas escolas. A fiscalização desses estabelecimentos é necessária, juntamente com ações educativas destinadas aos proprietários das cantinas, escolares, pais e professores.

Termos de indexação: Cantina escolar. Lei das cantinas. Alimentação escolar.

\section{A B S T R A C T}

\section{Objective}

The objective of this study was to verify the existence of canteens in Florianópolis and the foods and beverages that they are selling after the institution of the State Law of Regulation of Canteens.

\section{Methods}

A structured questionnaire was administered by telephone to the school principals or the person in charge of the canteens in the elementary schools of Florianópolis. The data were processed and analyzed by the software SPSS 10.0 .

\section{Results}

Of the 117 institutions of the municipality in 2006, 89.7\% participated. Of these, $53.3 \%$ of these schools had canteens where 31 were private schools, 22 were state schools and only 3 were municipal schools. The main reasons for the absence of canteens in public schools were the existence of the School Food Program and the requirements imposed by this Law. Amongst the foods forbidden by this Law are fried and other commercial snacks. The majority of the schools do not sell soft drinks (98.2\%) or commercial pop corns (92.9\%). Natural juices and baked homemade snacks are sold by $75.0 \%$ and $98.2 \%$ of the schools, respectively. On the other hand, $60.7 \%$ of the schools sell artificially-flavored juices. The Law requires that the canteens sell two types of seasonal fruits, but $60.7 \%$ of them do not sell fruits or fruit salads.

\section{Conclusion}

Items prohibited by the Law were rarely or no longer sold; however, foods of low nutritional value are still being sold in many schools. It is necessary to inspect these establishments and provide nutritional education for canteen owners, students, parents and teachers.

Indexing terms: School canteen. Law of schools canteens. School feeding.

\section{N T R O D U Ç Ã O}

No Brasil, sabe-se que o acesso aos alimentos no ambiente escolar pode ocorrer por meio de fontes diversas, sendo uma delas as cantinas escolares. Portaria da região metropolitana da Grande São Paulo define cantina escolar como uma dependência dentro do estabelecimento de ensino, destinada a fornecer serviços de alimentação a alunos, professores e demais funcionários, mediante pagamento ${ }^{1}$.

O debate em torno da regulamentação ou da adoção de medidas que possam transformar as cantinas escolares e os serviços de alimentação escolar em locais que garantam o fornecimento de alimentos saudáveis vem assumindo dimensão internacional. Inúmeros países estão construindo alternativas para o ambiente escolar, procurando intervir nos elevados números de casos de sobrepeso e obesidade infanti|2,3.

Em 4 de junho de 2001, foi aprovada em Florianópolis, Santa Catarina (SC), a Lei municipal $n^{\circ}$ 5.853, para as unidades educacionais públicas e privadas que atendem a educação básica ${ }^{4}$. Inédita no País até aquele momento, a Lei determina a proibição do comércio dos seguintes itens nas cantinas: bebidas alcoólicas; balas, pirulitos e 
gomas de mascar; refrigerantes e sucos artificiais; salgadinhos industrializados; salgados fritos e pipocas industrializadas.

Com ampla divulgação na mídia nacional, a Lei $n^{\circ} 5.853^{4}$ foi estendida para todo o Estado de SC como Lei Estadual n 12.061, em 18 de dezembro de $2001^{5}$. O artigo $1^{\circ}$ da Lei Estadual determina que os serviços de lanches e bebidas nas unidades públicas e privadas da educação básica, localizadas no Estado de Santa Catarina, deverão obedecer a padrões de qualidade nutricional e de vida indispensáveis à saúde dos alunos. Além de também referir como expressamente proibida a comercialização dos itens citados pela Lei municipal $n^{\circ}$ 5.853, a Lei $n^{\circ} 12.061$, ainda obriga as cantinas a oferecerem duas opções de frutas sazonais diariamente. Com essa Lei, as cantinas tornaram-se obrigadas a comercializar produtos considerados mais saudáveis $5^{5,6}$.

A partir da criação da Lei de Regulamentação das Cantinas de Santa Catarina, estratégias semelhantes têm sido observadas em diferentes municípios e estados brasileiros, como no município do Rio de Janeiro ${ }^{7}$ - posteriormente estendida também para o Estado do Rio de Janeiro ${ }^{8}$, no município de Belo Horizonte $(\mathrm{MG})^{9}$, no Estado do Paraná10 ${ }^{10}$ na Grande São Paulo1 ${ }^{1}$, no Distrito Federal ${ }^{11}$, no Município de Natal (RN) ${ }^{12}$ e no município de Porto Alegre (RS) ${ }^{13}$.

Como ponto comum entre algumas medidas legislativas, ressalta-se que cinco proíbem a divulgação de propagandas dos alimentos proibidos no ambiente escolar7,8,9,11,12. A Lei municipal de Porto Alegre também faz referências às propagandas, proibindo a exposição de cartazes publicitários que estimulem a aquisição e o consumo de balas, chicletes, salgadinhos e refrigerantes ${ }^{13}$. Três Leis referem-se à obrigatoriedade da presença de frutas na cantina escolar ${ }^{1,5,10}$. Outro item importante é a presença obrigatória de mural ou material de comunicação visual para divulgação de informações relacionadas à alimentação e nutrição ${ }^{1,4,5,10}$.

Essas medidas têm sido reconhecidas como importantes estratégias de promoção de hábitos alimentares saudáveis, visando à prevenção de doenças causadas pela alimentação escolar inadequada ${ }^{14-16}$.

Ainda para reforçar as orientações citadas acima, o Ministério da Saúde (MS) lançou em 2004 os "Dez Passos para a Promoção da Alimentação Saudável nas Escolas", como um conjunto de estratégias para propiciar a adesão da comunidade escolar a hábitos alimentares saudáveis e atitudes promotoras da saúde ${ }^{17}$.

Torna-se interessante mencionar também a emissão da Portaria Interministerial no 1.010 de 8 de maio de 2006, pelos Ministros da Educação e da Saúde, que instituiu as diretrizes para a promoção da alimentação saudável nas escolas de educação infantil, ensino fundamental e ensino médio das redes públicas e privadas, em âmbito nacional. A portaria traz alguns eixos prioritários, dentre os quais se destacam: restrição ao comércio e à promoção de alimentos e preparações com altos teores de gordura saturada, gordura trans, açúcar livre e sal e incentivo ao consumo de frutas, legumes e verduras ${ }^{18}$.

O objetivo deste artigo é realizar um diagnóstico sobre a existência das cantinas escolares no município de Florianópolis, Santa Catarina, verificando os alimentos e bebidas nelas comercializados.

\section{MÉ TO D O S}

Este foi um estudo de corte transversal, cuja coleta de dados foi realizada no período de junho a julho de 2006, tendo como população estudada o universo das escolas de ensino fundamental das redes municipal, estadual e particular do município de Florianópolis.

Junto ao censo escolar de 2006, realizado pelo Setor de Estatística da Secretaria de Estado da Educação, constatou-se um total de 117 escolas no município de Florianópolis vinculadas a dois tipos de administração: órgãos públicos e empresas privadas. Por se tratar de uma investigação de participação voluntária, a taxa de 
adesão foi de 89,7\% (105 escolas) do universo das instituições do município. As 12 instituições restantes não foram entrevistadas por insucesso das chamadas telefônicas (2 escolas), recusas por parte dos membros da coordenação escolar e/ou alegação de falta de interesse em participar da investigação (10 escolas).

O questionário utilizado para a obtenção dos dados foi constituído de quatro perguntas curtas e simples, que abordavam: (a) existência de cantina na escola, (b) motivos para a não existência de cantina, (c) responsável pela cantina e (d) venda informal de alimentos dentro da área escolar. Utilizando-se a definição de cantina escolar proposta pela Portaria da Grande São Paulo1, optou-se que, para ser considerado como cantina, o estabelecimento de ensino deveria contar com uma dependência interna que fornecesse alimentação mediante pagamento. Além da existência de cantina, perguntou-se ao entrevistado se havia pontos de venda informal de alimentos dentro da área escolar, considerando-se que esses locais não se enquadravam na definição de cantina adotada'.

Além disso, o questionário também apresentava uma lista com 16 alimentos ou grupos de alimentos e bebidas usualmente vendidos em cantinas escolares. O entrevistado deveria informar se os produtos da lista eram ou não comercializados pela cantina da escola. Contou-se com a assessoria de nutricionistas das Secretarias Municipal e Estadual de Educação, para a definição dessa listagem, que se baseou na relação de itens proibidos pela Lei de Regulamentação das Cantinas de Santa Catarina, englobando ainda itens referidos por outras medidas legislativas nacionais.

A aplicação dos questionários foi feita por meio de entrevistas realizadas por telefone com os diretores das escolas ou responsáveis pelas cantinas. Quando, ao primeiro contato com a escola, tais funcionários não estavam disponíveis ou as chamadas não eram atendidas, os entrevistadores retornavam a ligação (por no mínimo 10 vezes) durante o período de coleta de dados.
Ao participante fazia-se uma breve apresentação da pesquisa e seus objetivos antes da aplicação do questionário. Em se tratando de entrevistas por telefone, o termo de consentimento livre e esclarecido foi verbal, obtido por ocasião dos contatos telefônicos com os entrevistados. Antes do início da coleta de dados, foi enviada uma correspondência para cada instituição de ensino, explicando os objetivos e os procedimentos da pesquisa.

A equipe de entrevistadores foi composta por quatro acadêmicas do último ano do curso de graduação em Nutrição da Universidade Federal de Santa Catarina (UFSC). A equipe foi treinada para a realização das entrevistas telefônicas, tendo sido realizado teste piloto em duas escolas de Florianópolis. Após o teste, o instrumento foi adaptado e corrigido, e foi aplicado no conjunto de instituições que aceitaram participar da investigação, incluindo-se, novamente, as duas escolas do teste piloto. Os dados foram processados e analisados de modo descritivo, utilizando-se o software SPSS versão 10.0.

Este estudo representa um subprojeto de uma pesquisa mais ampla, que teve por objetivo geral acompanhar o processo de implementação da Lei de Regulamentação das Cantinas sobre os hábitos alimentares e o estado nutricional dos alunos do ensino fundamental catarinense (Conselho Nacional de Desenvolvimento Científico e Tecnológico, processo n 402334/2005-1). A pesquisa foi aprovada pelo Comitê de Ética de Pesquisa com Seres Humanos da Universidade Federal Santa Catarina (projeto $n^{\circ}$ 031/06).

\section{RES U LTA DOS}

Das 117 instituições escolares do município de Florianópolis com ensino fundamental em 2006, 105 (89,7\%) aceitaram participar da presente pesquisa, sendo 33 municipais, 37 estaduais e 35 particulares.

Dentre as escolas participantes, 56 $(53,3 \%)$ possuíam cantina, sendo 31 particulares 
e 25 públicas. Somente 3 escolas municipais $(9,1 \%)$ relataram possuir cantina, enquanto 22 escolas estaduais $(59,5 \%)$ possuem esse estabelecimento. Nas particulares, a presença de cantina é mais marcante, havendo cantina em 31 (88,6\%) instituições.

O principal motivo apontado pelos entrevistados das escolas públicas para a ausência de cantina foi a alimentação oferecida pelo Programa Nacional de Alimentação Escolar (PNAE), aliada à instituição da Lei de Regulamentação das Cantinas de Santa Catarina. Do total de 45 escolas públicas sem cantina, 93,3\% apresentou essa justificativa para a inexistência do estabelecimento em questão. Com relação às quatro escolas particulares que referiram não possuir cantina no ambiente escolar, três $(75,0 \%)$ justificaram a inexistência pela adoção do sistema de "lanches coletivos" e a outra escola fez menção à Lei de Regulamentação das Cantinas como motivo de inexistência.

Quando questionados a respeito da responsabilidade pela cantina, a maioria dos entrevistados $(60,7 \%)$ das 56 escolas que a possuíam revelou tratar-se de cantina terceirizada, enquanto nas demais instituições de ensino as cantinas eram de responsabilidade da própria escola.

Embora $46,7 \%$ das escolas investigadas não possuíssem cantina, $26,7 \%$ relataram a existência de venda informal de alimentos dentro da área escolar. Na maioria dos casos (96,4\%), esse tipo de comércio era realizado pelos alunos para arrecadação de fundos para formaturas.

A Tabela 1 apresenta os alimentos comercializados nas escolas, separadas por rede de ensino, conforme a presença ou ausência na cantina escolar.

Com relação a alguns dos itens proibidos pela Lei de Regulamentação das Cantinas de SC e por outras medidas nacionais, salienta-se que 100,0\% dos entrevistados relataram ausência de salgados fritos e industrializados nas cantinas. A ausência de refrigerantes e de pipocas industrializadas foi referida por $98,2 \%$ e $92,9 \%$ dos entrevistados, respectivamente. Embora proibida pela Lei, mais da metade dos entrevistados $(60,7 \%)$ relatou a comercialização de sucos artificiais nas cantinas, sendo as escolas particulares as que mais se referiram à venda dessas bebidas $(67,7 \%)$.

Tabela 1. Alimentos e bebidas comercializados pelas cantinas escolares do município de Florianópolis (SC), 2006.

\begin{tabular}{|c|c|c|c|c|c|c|c|c|}
\hline \multirow[b]{2}{*}{ Alimentos } & \multicolumn{2}{|c|}{ Pública municipal } & \multicolumn{2}{|c|}{ Pública estadual } & \multicolumn{2}{|c|}{ Particular } & \multicolumn{2}{|c|}{ Total } \\
\hline & $\mathrm{n}$ & $(\%)$ & $\mathrm{n}$ & $(\%)$ & $\mathrm{n}$ & $(\%)$ & $\mathrm{n}$ & $(\%)$ \\
\hline Balas, confeitos, doces e chocolates & 1 & 33,3 & 2 & 9,1 & 12 & 38,7 & 15 & 26,8 \\
\hline Biscoitos salgados & - & - & 7 & 31,8 & 22 & 71,0 & 29 & 51,8 \\
\hline Biscoitos doces & 1 & 33,3 & 5 & 22,7 & 19 & 61,3 & 25 & 44,6 \\
\hline Bolos e tortas doces & 1 & 33,3 & 13 & 59,1 & 25 & 80,6 & 39 & 69,6 \\
\hline Cachorro-quente & 1 & 33,3 & 12 & 54,5 & 17 & 54,8 & 30 & 53,6 \\
\hline Frutas frescas ou saladas de frutas & - & - & 3 & 13,6 & 19 & 61,3 & 22 & 39,3 \\
\hline Leite ou bebidas à base de leite & 1 & 33,3 & 6 & 27,3 & 23 & 74,2 & 30 & 53,6 \\
\hline Picolé à base de frutas & 1 & 33,3 & 3 & 13,6 & 7 & 22,6 & 11 & 19,6 \\
\hline Picolé artificial ou cremoso ou sorvete & - & - & 4 & 18,2 & 7 & 22,6 & 11 & 19,6 \\
\hline Pipoca industrializada & - & - & 2 & 9,1 & 2 & 26,5 & 4 & 7,1 \\
\hline Refrigerante & - & - & - & - & 1 & 3,2 & 1 & 1,8 \\
\hline Salgados assados & 3 & 100,0 & 21 & 95,5 & 31 & 100,0 & 55 & 98,2 \\
\hline Salgados fritos & - & - & - & - & - & - & - & - \\
\hline Salgadinhos industrializados & - & - & - & - & - & - & - & - \\
\hline Sanduíches ${ }^{*}$ & 3 & 100,0 & 12 & 54,5 & 28 & 90,3 & 43 & 76,8 \\
\hline Suco artificial & 1 & 33,3 & 12 & 54,5 & 21 & 67,7 & 34 & 60,7 \\
\hline Suco natural de frutas & 2 & 66,7 & 13 & 59,1 & 27 & 87,1 & 42 & 75,0 \\
\hline
\end{tabular}

*Foram incluídos nesta categoria os sanduíches de modo geral, englobando os sanduíches naturais, e excluídos os que continham hambúrguer e/ou ovo. 
196 | C.G. GABRIEL et al.

A maioria dos entrevistados $(73,2 \%)$ relatou ausência de balas, confeitos, doces e chocolates.

Com relação aos bolos e tortas, 69,6\% dos entrevistados referiram a presença de tais alimentos. A maioria $(80,4 \%)$ referiu ausência de picolés à base de frutas, artificiais, cremosos ou sorvetes. De acordo com os entrevistados, as escolas particulares também apresentaram maior disponibilidade de alimentos desse grupo e do anterior.

O oferecimento de cachorro-quente pelas cantinas foi referido por 53,6\% dos entrevistados. Biscoitos salgados e doces foram referidos por $51,8 \%$ e $44,6 \%$ dos entrevistados, respectivamente.

Dentre os alimentos considerados mais saudáveis pelo Ministério da Saúde ${ }^{17}$, destaca-se que a presença de salgados assados foi citada por 98,2\% entrevistados. Ainda, 75,0\% dos participantes referiram a disponibilidade de sucos naturais; $76,8 \%$ de sanduíches e 53,6\% de leites ou bebidas à base de leite. Os entrevistados das instituições particulares também relataram maior presença desses itens nas cantinas, quando comparadas às respostas obtidas nas escolas públicas.

Somente 39,3\% dos entrevistados relataram a oferta de frutas ou saladas de frutas, sendo a disponibilidade dentre as escolas particulares superior (61,3\% nas particulares vs $0 \%$ nas municipais e $13,6 \%$ nas estaduais).

\section{I S C U S S Ã O}

A universalidade da escola como meio facilitador de acesso às crianças e adolescentes destaca seu papel nos esforços globais de combate aos problemas contemporâneos de saúde publica $^{19}$.

Ressalta-se que a Lei de Regulamentação das Cantinas de Santa Catarina proíbe a comercialização de balas, pirulitos e gomas de mascar, não fazendo referências aos chocolates e/ou demais doces ${ }^{5}$. No entanto, outras medidas, como a Lei Estadual do Paraná ${ }^{10}$ e do Rio de Janeiro ${ }^{8}$ proíbem também a comercialização de chocolates, doces a base de goma e caramelo.

Os "Dez Passos para a Promoção da Alimentação Saudável nas Escolas" 17 , reforçam que são considerados alimentos não saudáveis: balas; pirulitos; gomas de mascar; biscoitos, principalmente os recheados; refrigerantes; sucos artificiais ou adoçados; frituras como rissoles, pastéis e coxinhas; maionese; salgados com salsichas e presuntos/apresuntados; salgadinhos de pacote; pipocas industrializadas e outros com o perfil acima descrito. Os alimentos proibidos pela Lei $n^{\circ} 12.061 / 2001^{5}$ estão de acordo com os citados pelo Ministério da Saúde ${ }^{17}$.

Embora fatores positivos tenham sido revelados neste estudo, a destacar a ausência de salgados fritos e industrializados e a quase total exclusão de refrigerantes e pipocas industrializadas nas cantinas das escolas públicas e privadas, alimentos saudáveis como as frutas frescas aparecem de forma discreta entre as cantinas públicas.

As escolas particulares destacaram-se pela maior comercialização de frutas frescas e saladas de frutas, leite ou produtos à base de leite, sanduíches e sucos naturais de frutas. A presença desses produtos ocorre em menor proporção nas cantinas das instituições públicas de ensino. Entretanto o destaque das escolas particulares não se deu somente pela maior ocorrência de opções mais saudáveis nas cantinas. Itens como bolos e tortas, sucos artificiais, balas, confeitos, doces e chocolates também apresentaram maior ocorrência nessas instituições.

Estudos anteriores revelaram que alguns alimentos de baixo valor nutricional oferecidos nas cantinas são, muitas vezes, preferidos pelos escolares em detrimento de alimentos saudáveis, o que pode contribuir para o consumo excessivo de gordura saturada e desenvolvimento de obesidade $20-22$

O documento resultante da II Conferência Nacional de Segurança Alimentar e Nutricional, realizada em 2004, salienta que a cantina, como parte do ambiente escolar, poderia ser vista como 
um espaço educativo importante para estimular o consumo de determinados alimentos, influenciando escolhas saudáveis em função do que está exposto à venda ${ }^{23}$.

Promoções especiais que incentivem a aquisição de alimentos considerados saudáveis, como frutas frescas e sucos naturais, podem ser estratégias eficazes para estimular hábitos alimentares saudáveis entre os escolares. French ${ }^{24}$, em estudo que avaliou o efeito dos preços nas escolhas alimentares de escolares adolescentes norte-americanos, constatou que uma redução nos preços das frutas comercializadas no ambiente escolar aumentou o seu consumo.

Destaca-se que, na maioria das escolas da América Latina, existem refeitórios e cantinas escolares, fazendo-se necessário avaliar o tipo de alimentos que se oferece aos alunos, procurando garantir, na oferta, opções para que possam escoIher alimentos saudáveis ${ }^{25}$.

As medidas legislativas nacionais trazem como meta prevenir os vários agravos à saúde relacionados com a alimentação inadequada. Louvadas as iniciativas das esferas estaduais e municipais, é necessário abordar essa questão em âmbito nacional a fim de estabelecer normas gerais e diretrizes para desencadear um conjunto de ações que visem à educação nutricional e à educação em saúde. A Portaria Interministerial 1.010 parece ser o primeiro passo para desenvolver ações nesse sentido ${ }^{18}$. Salienta-se que para a efetiva incorporação de hábitos saudáveis à comunidade escolar, é necessário que gestores, universidades e nutricionistas, dentre outros, apóiem tal medida com ações e orientações efetivas a curto, médio e longo prazo.

Este artigo destaca a importância de uma abordagem legislativa múltipla que possa confluir para uma única direção: impulsionar as escolas a oferecerem produtos mais saudáveis e as crianças a recriarem seus hábitos alimentares e influenciarem positivamente seus pais e familiares.

Apesar de se encontrarem medidas legislativas que regulamentam os alimentos que deve- rão ser disponibilizados nas escolas, ressalta-se a necessidade da realização de pesquisas nacionais que considerem esse campo de estudo, tendo em vista que não foi encontrada nenhuma pesquisa nacional sobre esse tema.

A utilização de todos os espaços escolares para o desenvolvimento de atividades educativas em nutrição pode ser um meio eficaz para a promoção de hábitos alimentares saudáveis na comunidade escolar. Reforça-se, ainda, a importância do profissional nutricionista na conscientização de alunos e pais para a prática de hábitos alimentares saudáveis na escola. Sabe-se que a conscientização não é um processo imediato, exigindo tempo e dedicação. Assim, o desenvolvimento de medidas paralelas, como não ofertar produtos inadequados no ambiente escolar e oferecer opções variadas e atrativas, ajudaria as crianças e jovens a escolherem alimentos alternativos e desenvolverem hábitos alimentares saudáveis.

Recorda-se ainda que as 12 recusas encontradas (10,3\% do universo de escolas do município em questão) podem ter refletido nos resultados encontrados, atentando-se para a importância da conscientização adequada dos atores envolvidos quanto à relevância de sua participação.

\section{O N C L U S Ã O}

Embora fatores positivos tenham sido revelados neste estudo, itens proibidos e considerados de baixo valor nutricional continuam sendo comercializados em muitas escolas. Os dados encontrados atentam para a necessidade de as redes de ensino de Florianópolis adequarem-se à Lei.

Reconhece-se que o problema da obesidade em escolares não será resolvido apenas com a proibição de alimentos calóricos nas escolas ou com a limitação da publicidade. Faz-se necessária a ação conjunta de pais, professores, profissionais da saúde, proprietários de cantinas escolares, legisladores e publicitários, entre outros, para promover ambientes e estratégias propícias à promoção de 
hábitos alimentares saudáveis, e para incentivar também a prática de exercícios físicos entre os escolares.

Além disso, ressalta-se que a fiscalização das cantinas escolares é necessária, juntamente com as ações educativas e estratégias direcionadas aos responsáveis pelas cantinas, visando qualificar o fornecimento de alimentos e, consequentemente, os hábitos alimentares.

Considera-se oportuno enfatizar que proprietários de cantinas escolares precisam ser capacitados e preparados para trabalhar com alimentação escolar, de modo que essas ações possibilitem uma conscientização e entendimento por parte deles acerca dos motivos pelos quais foram criadas medidas legislativas para regulamentar cantinas e estabelecimentos similares.

O presente estudo não verificou quais alimentos e bebidas são comercializados através da venda informal. Julga-se importante verificar se estes itens estão em conformidade com a Lei, uma vez que as escolas podem estar disponibilizando alimentos inadequados por meio desse tipo de comércio.

\section{COLABORADORES}

C.G. GABRIEL e M.V. SANTOS realizaram a coleta dos dados, o levantamento e a revisão da literatura e a redação do artigo. F.A.G. VASCONCELOS orientou o desenho metodológico da investigação e revisou o artigo. G.H.G. MILANEZ e S.B. HULSE participaram da discussão e da revisão crítica do artigo.

\section{REFERÊ N CIAS}

1. São Paulo. Normas para funcionamento de cantinas escolares. Portaria Conjunta COGSP/CEI/ DSE, de 23 de março de 2005. [acesso 2007 mar 5]. Disponível em: <http://dersv.sites.uol.com.br/ port_conj_CEl_cantina.htm>.

2. Passos E, Magalhaes NP, Gonçales NMEF, Moura VHV, Silva EB. Alimentação saudável nas escolas. Rev Inf Legis [Internet] 2006 [acesso 2007 out 8]; 43(170):323-28. Disponível em: <http://www. senado.gov.br/web/cegraf/ril/Pdf/pdf_170/R17023. $p d f>$.
3. Brasil. Ministério da Saúde. Regulamentação da comercialização de alimentos em escolas no Brasil: experiências estaduais e municipais. Brasília: Ministério da Saúde; 2007.

4. Santa Catarina. Lei n. 5853, de 4 de junho de 2001. Dispõe sobre os critérios de concessão de serviços de lanches e bebidas, nas unidades educacionais, localizadas no município de Florianópolis. 2001 [acesso 2007 ago 10]. Disponível em: <http://www. leismunicipais.com.br/cgi-local/leis2.pl>.

5. Santa Catarina. Lei $n^{\circ} 12.061$, de 18 de dezembro de 2001. Dispõe sobre critérios de concessão de serviços de lanches e bebidas nas unidades educacionais, localizadas no Estado de Santa Catarina. 2001. Diário Oficial do Estado de Santa Catarina. 200120 dez; n.16.810.

6. Santa Catarina. Secretaria de Estado da Educação e Inovação. Planejamento da alimentação escolar no município. Florianópolis: SED; 2003.

7. Rio de Janeiro. Decreto $n^{\circ} 21.217$, de 1 de abril de 2002. Proíbe no âmbito das unidades escolares da rede municipal de ensino adquirir, confeccionar, distribuir e consumir os produtos que menciona. Diário Oficial do Município, p.9, de 2 abr 2002. [acesso 2007 mar 3]. Disponível em: <http://www2. rio.rj.gov.br/governo/vigilanciasanitaria/legislacao/ decmunicipal21217_02.pdf>.

8. Rio de Janeiro. Lei $n^{\circ} 4.508$, de 11 de janeiro de 2005. Proíbe a comercialização, aquisição, confecção e distribuição de produtos que colaborem para a obesidade infantil, em bares, cantinas e similares instalados em escolas públicas e privadas do Estado do Rio de Janeiro, na forma que menciona. Diário Oficial [Internet]. 200512 jan; [acesso 2007 mar 3]. Disponível em: <http://www.see.rj. gov.br/coie/NOVIDADES/le0504508.pdf>.

9. Belo Horizonte. Lei n 8.650, de setembro de 2003. Dispõe sobre a proibição, em escola da rede pública municipal de ensino, de adquirir, confeccionar, distribuir e comercializar os produtos que menciona e dá outras providências. [acesso 2007 mar 3]. Disponível em: <http://www.cmbh.mg. gov.br>

10. Paraná. Lei n 14.855 de 19 de outubro de 2005. Dispõe sobre padrões técnicos de qualidade nutricional, a serem seguidos pelas lanchonetes e similares, instaladas nas escolas de ensino fundamental e médio, particulares e da rede pública. [acesso 2007 abr 8]. Disponível em: <http://www.pr. gov.br/casacivil/legislacao.shtml>.

11. Distrito Federal. Lei $n^{\circ} 3.695$, de 8 de novembro de 2005. Dispõe sobre a promoção da alimentação saudável nas escolas da rede de ensino do Distrito Federal. Lex: Diário Oficial do Distrito Federal [Internet]. 2005 [acesso 2007 abr 5]. Disponível 
em:<http://www.fibra.org.br/publico/setores/000/ 23/catalogo/1/11/106/agora\% C3\%A9lei-n\%C 2\%BA07-05.pdf>.

12. Natal. Lei $n^{\circ} 0245$, de 16 de agosto de 2006. Dispõe sobre padrões técnicos de qualidade nutricional, a serem seguidos pelas lanchonetes e similares, instaladas nas escolas de ensino fundamental e médio, particulares e da rede pública e dá outras providências. Lex: Diário Oficial do Município [Internet]. 2006 [acesso 2007 abr 8]. Disponível em: <http://www.natal.rn.gov.br/dom/arquivos_ anexos/dom_20060817.pdf>.

13. Porto Alegre. Lei $n^{\circ} 10.167$, de 24 de janeiro de 2007. Estabelece, no Município de Porto Alegre, normas para o controle da comercialização de produtos alimentícios e de bebidas nos bares e nas cantinas das escolas públicas e privadas e dá outras providências. [acesso 2007 abr 5]. Disponível em: <http://www.mp.rs.gov.br/infancia/legislacaod legislacaoc/id3400.htm>.

14. Pilant VB. Position of the American Dietetic Association: local support for nutrition integrity in schools. J Am Diet Assoc. 2006; 106(1):122-33. doi: 10.1016/j.jada.2005.11.006.

15. Austin SB, Fung T, Cohen-Bearak A, Wardle K, Cheung LW. Facilitating change in school health: a qualitative study of schools' experiences using the School Health Index. Prev Chronic Dis [Internet]. 2006 [cited 2007 Oct 2]; 3(2):A35. Available from: <http://www.ncbi.nlm.nih.gov/pmc/articles/ PMC 1564114/pdf/PCD32A35.pdf>.

16. Temple NJ, Steyn NP, Myburgh NG, Nel JH. Food items consumed by students attending schools in different socioeconomic areas in Cape Town, South Africa. Nutrition. 2006; 22(3):252-8. doi: 10.1016/j.nut.2005.07.013.

17. Brasil. Ministério da Saúde. Dez passos para a promoção da alimentação saudável nas escolas. Brasília; 2004 [acesso 2007 ago 18]. Disponível em: <http://dtr2004.saude.gov.br/nutricao/ documentos/dez_passos_pas_escolas.pdf > .

18. Brasil. Gabinete do Ministro. Portaria interministerial $n^{\circ} 1.010$, de 8 de maio de 2006. Institui as diretrizes para a promoção da alimentação saudável nas escolas de educação infantil, fundamental e nível médio das redes públicas e privadas, em âmbito nacional. Brasília; 2006 [acesso 2007 jun 12]. Disponível em: <http://dtr2004.saude.gov.br/ sas/legislacao/portaria1010_08_05_06.pdf>.

19. World Health Organization. Programmes and projects. Nutrition health topics. Nutrition-Friendly Schools Initiative. 2007 [cited 2007 Sept 3]. Available from: <http://www.who.int/nutrition/ topics/nut_school_aged/en/index.html>.

20. Story M, Kaphingst KM, French S. The role of schools in obesity prevention. Spring [Internet]. 2006 [cited 2007 Nov 2]; 16:109-42. Available from: <http://futureofchildren.org/futureof children/publications/docs/16_01_06.pdf>.

21. Ochsenhofer K, Quintella LCM, Silva EC, Nascimento APB, Ruga GMNA, Philippi ST, et al. O papel da escola na formação da escolha alimentar: merenda escolar ou cantina? Nutrire. 2006; 31(1): 1-16.

22. Mannino ML, Lee $Y$, Mitchell DC, Smiciklas-Wright $\mathrm{H}$, Birch LL. The quality of girls'diets declines and tracks across middle childhood. Int J Behav Nutr Phys Act. 2004; 1:1-11. doi: 10.1186/1479-58681-5.

23. Brasil. Conferência Nacional de Segurança Alimentar. Alimentação e educação nutricional nas escolas e creches. Brasília; 2005 [acesso 2008 abr 20]. Disponível em: <http://bvsms.saude.gov.br/bvs/ publicacoes/Il_Conferencia_2versao.pdf>.

24. French SA. Pricing effects on food choices. J Nutr [Internet]. 2003 [cited 2007 Oct 29]; 133(3): 841S-843S. Available from: <http://jn.nutrition.org/ cgi/reprint/133/3/841S>.

25. Ippolito-Shepherd J, Cerqueira MT, Ortega DP. Iniciativa Regional Escuelas Promotoras de la Salud en las Américas. IUHPE - Promotion \& Education [Internet]. 2005 [cited 2007 Out 8]; 12 (3-4): 220-9. Available from: <http://www.bvsde.paho.org/ bvsacd/cd57/EPS_IUHPE.pdf>.

Recebido em: 16/6/2008

Versão final reapresentada em: 2/4/2009 Aprovado em: 6/10/2009 